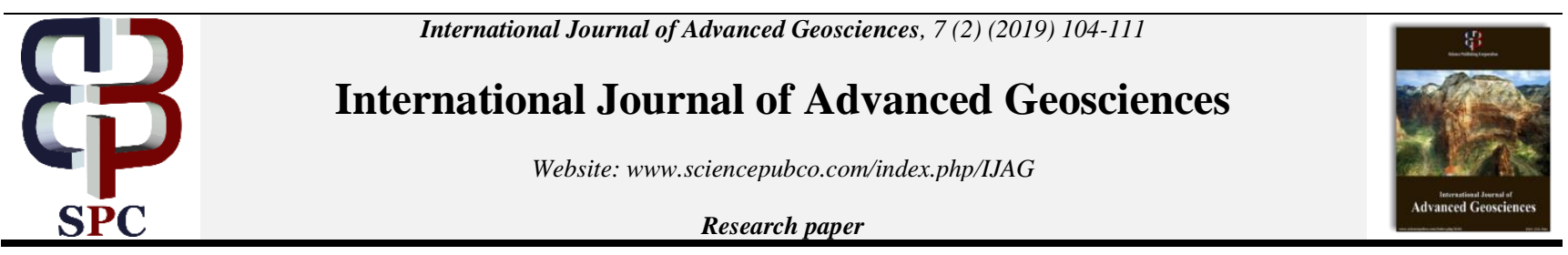

\title{
Improved definition of gas sand using elastic impedance attribute on an avo data over an $x$ field, Nigerian Niger delta
}

\author{
Ohakwere-Eze M. C. ${ }^{1}$, Igboekwe M. U. ${ }^{2}$, Chukwu G. U. ${ }^{3}$ \\ ${ }^{1}$ Department of Physics, Federal University of Kashere, Gombe State \\ ${ }^{2}$ Department of Physics, Michael Okpara University of Agriculture, Umudike, Abia State \\ *Corresponding author E-mail: michael.ohakwereze@gmail.com
}

\begin{abstract}
Elastic impedance (EI) inversion is considered one of the newest methods being used today in geophysical interpretation. Preliminary interpretation carried on the well logs revealed a hydrocarbon bearing sand from 8780 to $8900 \mathrm{ft}$. The average porosity value is $39 \%$ which suggest good porosity values for oil and excellent for gas reservoirs. The matched total resistivity values are likewise very high at about $90 \Omega \mathrm{m}$ with a very low density at that depth. The logs were modelled by creating the EI near and EI far logs from the input Vp, Vs and density logs at a defined angle of incidence of 2.5 for near angle and 45.0 for far angle. The EI Far log is lower than the EI Near log in the interpreted depth but higher in the rest of the log. This is further revealed in the crossplot showing the mapped gas sand at depth between 8780 and $8900 \mathrm{ft}$. Two Range limited stack were created from the seismic gathers with the first/near offset stack at $64 \mathrm{~m}$ and second/far offset stack at $196 \mathrm{~m}$. From each stack, a model each was created to get the near EI model and far EI model respectively from which inversion was done to generate the near and far inversion results. There is an improved definition of the gas sand on the far angle inversion with a stronger contrast represented by low values at the mapped seismic time window which corresponds to the mapped gas sand at same depth. This was further revealed on the crossplot. Inserting the crossplot on the near-Inversion volume with the mapped zone, the visible top of gas on the zone of interest was noticed. This zone confirmed where the elastic impedance at far-offsets is lower than the elastic impedance at near-offsets moreover agreed with the Elastic Impedance results on the logs. The Elastic Impedance attribute and its inversion technique has shown it is a strong and suitable tool in exploitation of gas zones as it has optimized the area of the gas zone approved by well logging process.
\end{abstract}

Keywords: Elastic Impedance; Logs; Inversion; Crossplot; Gas.

\section{Introduction}

Exploration for new reserves and recovery from existing accumulations have become increasingly challenging due to inadequate description and delineation of reservoir architecture using well logs, seismic and geological information (Ekine and Ibe 2013; Adewoye et al. 2015). Detailed petrophysical evaluation is usually required for optimized development and production, especially in the highly heterogeneous environments like the paralic successions of the Agbada formation of the Niger Delta area of Nigeria.

Elastic impedance, proposed by Connolly (1999), provided another approach to identify hydrocarbon anomalies using a partial stacking method. It has been proven to be a useful method for fluid and lithology discrimination. Inspired by the normal- incidence reflection coefficient defined by the acoustic impedance contrast between the lower and upper media, Connolly (1999) proposed an alternative expression for the $\mathrm{P}$-wave reflection coefficient at the given incidence angle in the following form:

$\mathrm{R}(\theta)=\frac{\mathrm{EI}_{2}-\mathrm{EI}_{1}}{\mathrm{EI}_{2}+\mathrm{EI}_{1}} \approx \frac{1}{2} \frac{\Delta \mathrm{EI}}{\mathrm{EI}} \approx \frac{1}{2} \Delta \ln (\mathrm{EI})$

Where EI is elastic impedance which is the function of P-wave velocity, S-wave velocity, and density.

Based on Aki and Richards' approximation for the Zoeppritz equation, substituting constant factor $\mathrm{k}=\left(\mathrm{V}_{\mathrm{s}} / \mathrm{V}_{\mathrm{p}}\right)^{2}$ and the equation $\Delta \mathrm{ln}$ $\mathrm{x}=\Delta \mathrm{x} / \mathrm{x}$, Aki-Richards equation can be reformulated:

$\Delta \ln (\mathrm{EI})=\Delta \ln \left(\mathrm{V}_{\mathrm{p}}^{\left(1+\tan ^{2} \theta\right)} \mathrm{V}_{\mathrm{S}}^{\left(-8 \mathrm{k} \sin ^{2} \theta\right)} \rho^{\left(1-4 \mathrm{k} \sin ^{2} \theta\right)}\right)$

Equation (2.30) can be rewritten to get the expression for EI: 
$\operatorname{EI}(\theta)=V_{p}^{\left(1+\tan ^{2} \theta\right)} V_{s}^{\left(-8 k \sin ^{2} \theta\right)} \rho^{\left(1-4 k \sin ^{2} \theta\right)}$

Where $\mathrm{k}=\left(\mathrm{V} / \mathrm{V}_{\mathrm{p}}\right)^{2}$. It is noticed that $\mathrm{EI}(0)$ is same as acoustic impedance (AI).

Resolution is controled by the lowest bandwidth (and widest angle), so processing must try to extract the most bandwidth from the greatest offsets (Cambois, 2001).

Connolly (1999) demonstrated the capability of EI to discriminate an oil sand from the background using a suite of logs.

\section{Research aim}

The research aim is to combine elastic impedance inversion with AVO analysis to improve the reservoir discrimination of the gas sand zone.

\section{Methodology}

Elastic impedance inversion is considered one of the newest methods being used today in geophysical interpretation. Traditional seismic lithology estimation involves taking the gathered data, stacking it, applying inversion, and calculating the estimate, using only acoustic impedance, which is not sufficient for estimating fluid content. AVO technology allows the operator to simultaneously estimate additional parameters to infer fluid and/or lithology.

In this research, inversion was combined with AVO analysis to enhance the reservoir discrimination. First the logs were modelled by creating the EI near and far logs from the input $\mathrm{V}_{\mathrm{p}}, \mathrm{V}_{\mathrm{s}}$ and density logs at a defined angle of incidence of $2.5^{\circ}$ for near angle and $45.0^{\circ}$ for far angle after which a crossplot was done.

Range limit stack processing of the seismic data can provide the near offset and far offset stack profiles. Near offset stack profile represents the elastic impedance for the small incident angles and far offset stack profile represents the elastic impedance for the larger incident angle. Examining the difference between these two stack profiles can infer the presence of hydrocarbon.

Two Range limited stack were created from the seismic gathers with the first/near offset stack at $64 \mathrm{~m}$ and second/far offset stack at $196 \mathrm{~m}$. From each stack, a model each was created to get the near EI model and far EI model respectively from which inversion was done to generate the near and far inversion results. Next the near-angle inversion and far-angle inversion were compared by crossplotting the two volumes.

\section{Results and discussion}

\subsection{Preliminary $\log$ analysis}

Low Gamma Ray values are more easily identified with the green fill color (fig 1). Low gamma ray values are a good indicator of sands. We can improve the interpretation of this well by examining the other logs (fig 2).

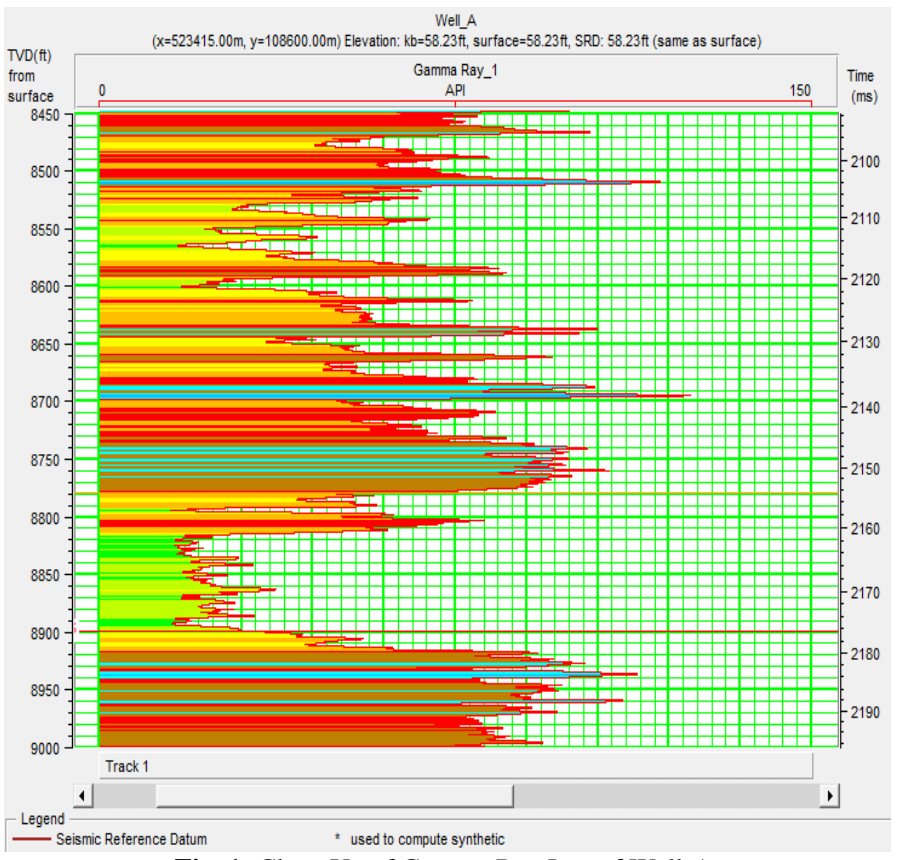

Fig. 1: Close-Up of Gamma Ray Log of Well-A 


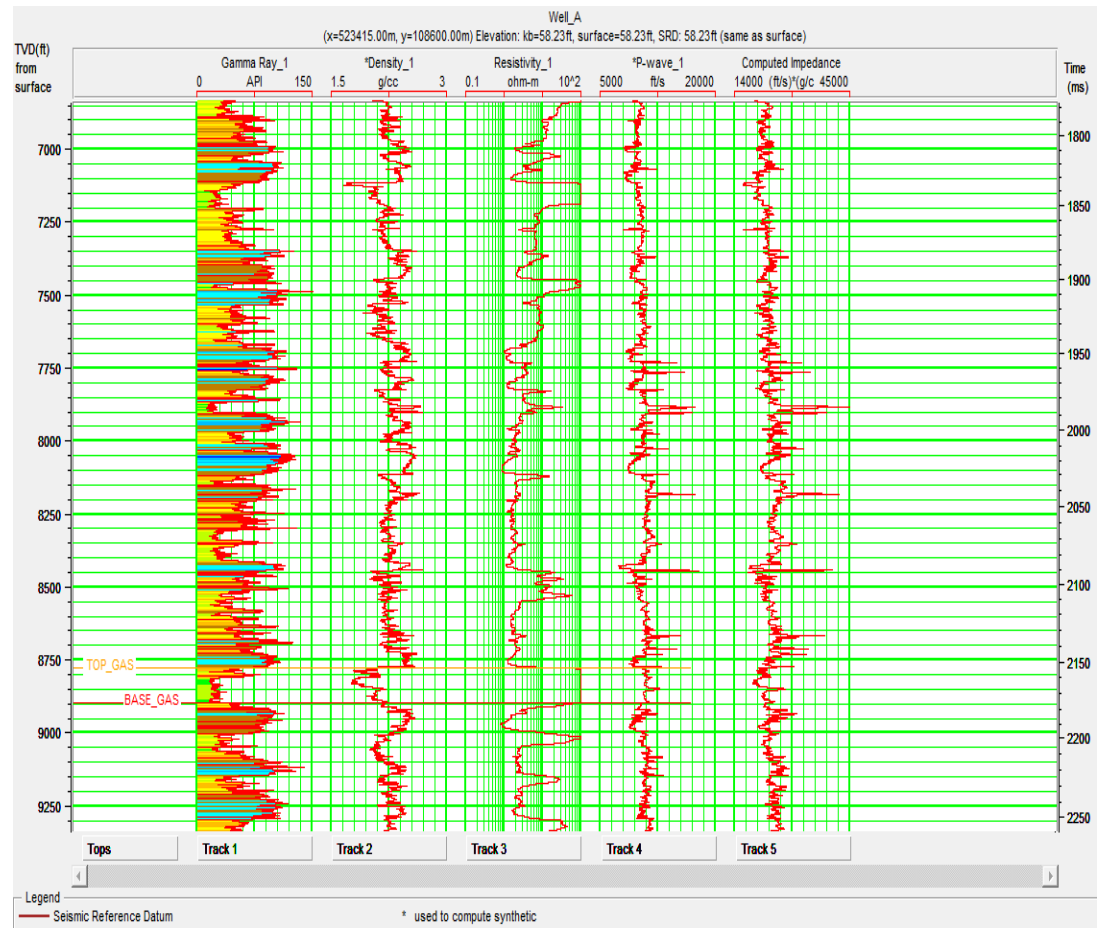

Fig. 2: Wireline Log Data For Well-A Showing Interpreted Mapped Sand Areas.

As seen in the well, the best reservoir is within deeper depth between 8780 and $8900 \mathrm{ft}$. The average porosity value is $39 \%$, which suggest good porosity values for oil and excellent for gas reservoirs. The matched total resistivity values are likewise very high at about $90 \Omega \mathrm{m}$ with a very low density at that depth.

\subsection{Elastic impedance (EI) extraction}

The logs were modelled by creating the EI near and far $\operatorname{logs}$ from the input $\mathrm{V}_{\mathrm{p}}, \mathrm{V}_{\mathrm{s}}$ and density $\operatorname{logs}$ at a defined angle of incidence of $2.5^{\circ}$ for near angle and $45.0^{\circ}$ for far angle.

Fig. 3 shows the logs after fluid substitution in the gas zone.

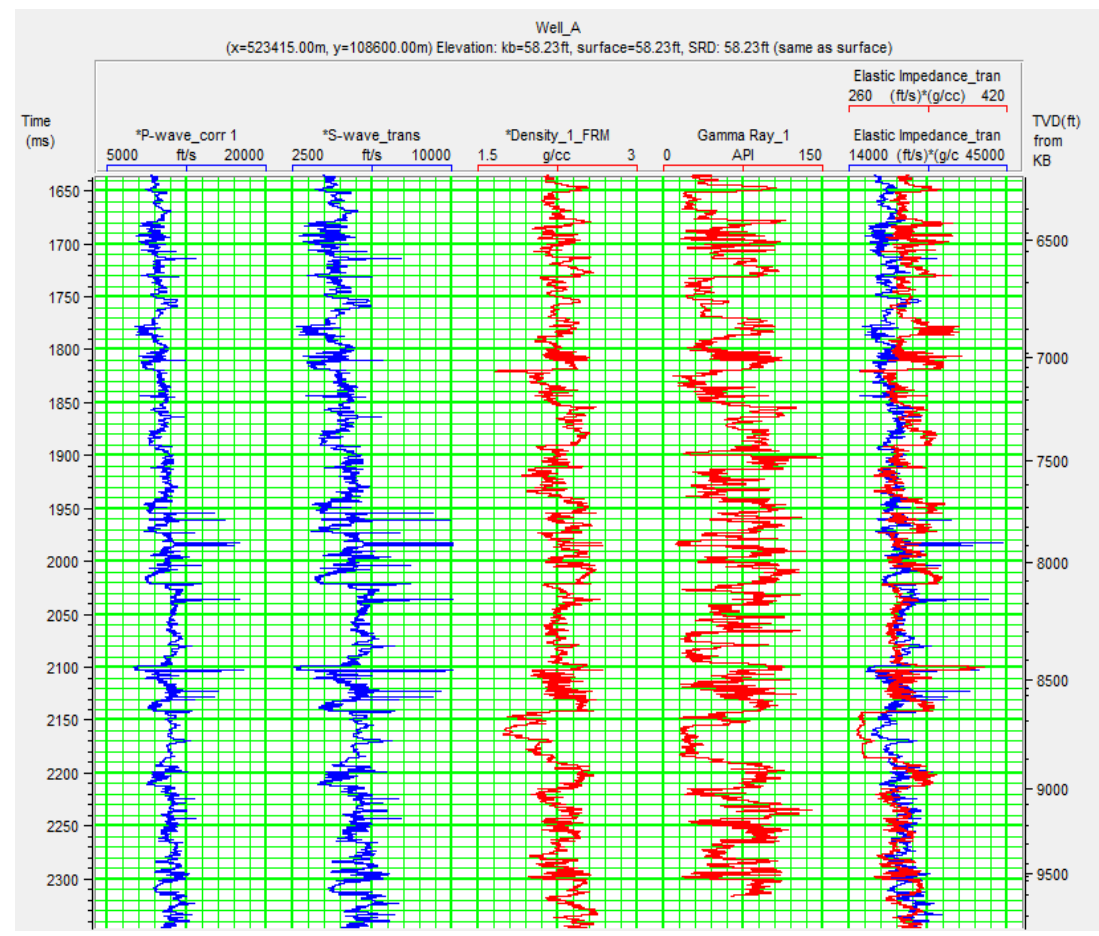

Fig. 3: Modeled Logs After Fluid Substitution.

A dramatic change in the elastic impedance response was noted when inversion was done for Elastic Impedance (EI) at the two different angles; $2.5^{\circ}$ and $45^{\circ}$. The EI Far $\log$ (red) is lower than the EI Near log (blue) in the gas zone but higher in the rest of the log. The interpreted crossplot between the near and far EI logs is shown in Fig. 4. 


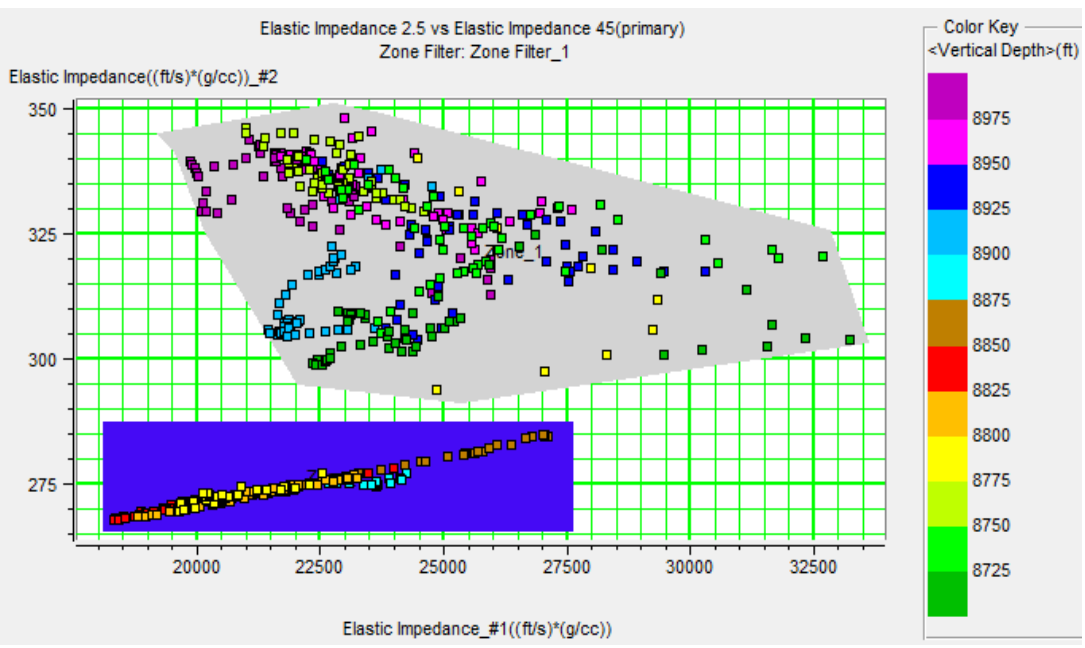

Fig. 4: Crossplot of EI-Near Against EI-Far Showing Mapped Zones.

The clear separation of the points on the lower left of the plot was noted.

Fig. 5 shows the zones marked on the logs themselves with the clear indication of the gas sand zone.

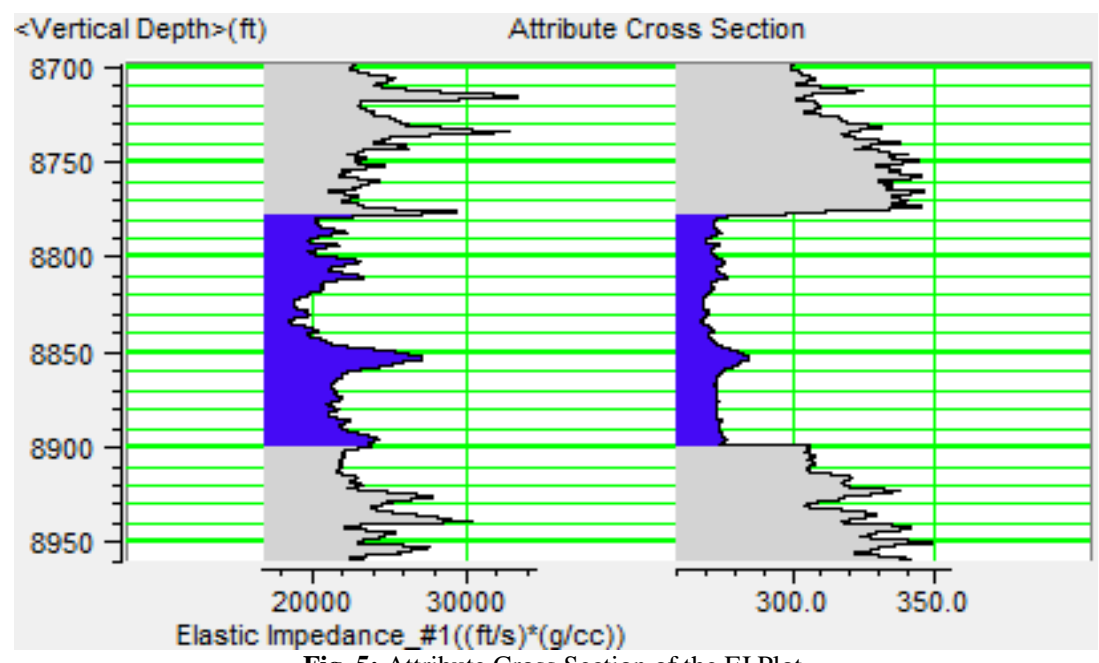

Fig. 5: Attribute Cross Section of the EI Plot.

\subsection{Range limited stacking}

Two Range limited stack were created from the seismic gathers (fig. 6) with the first/near offset stack at $64 \mathrm{~m}$ (fig. 7) and second/far offset stack at $192 \mathrm{~m}$ (fig. 8). The two offset stack were from $0-256 \mathrm{~m}$.

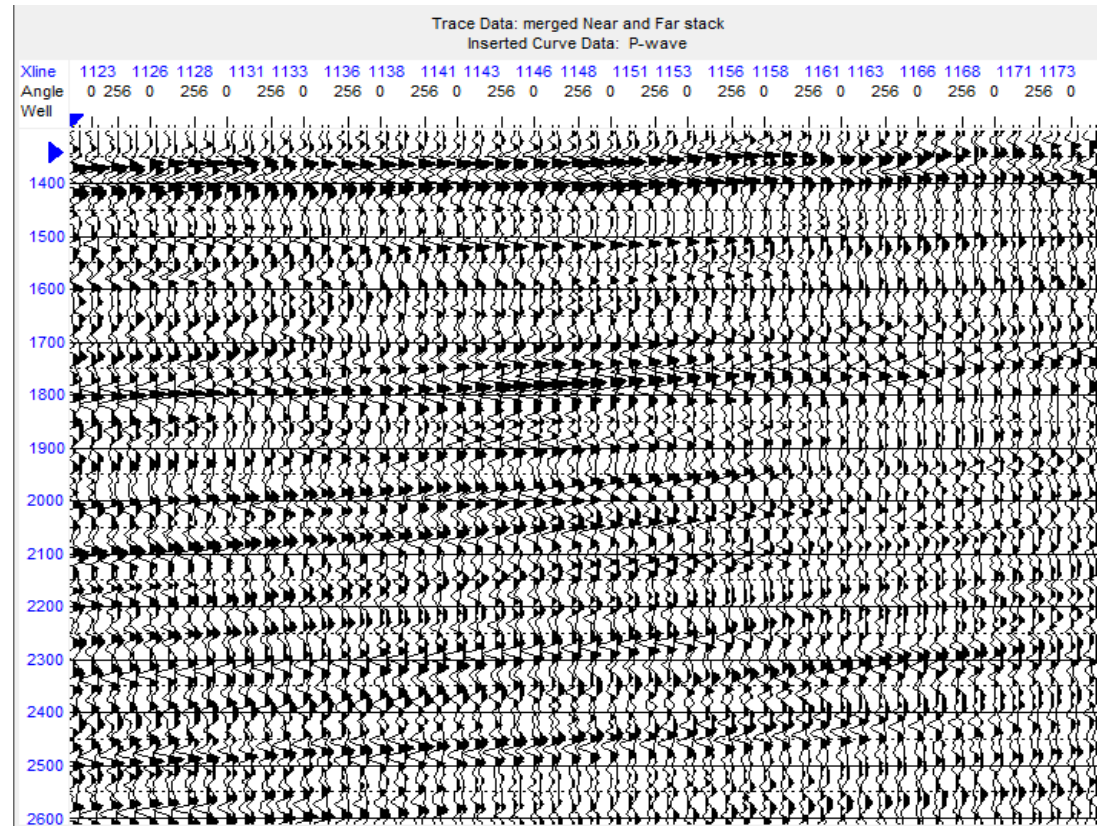

Fig. 6: Volume Display of the Merged Gathers. 

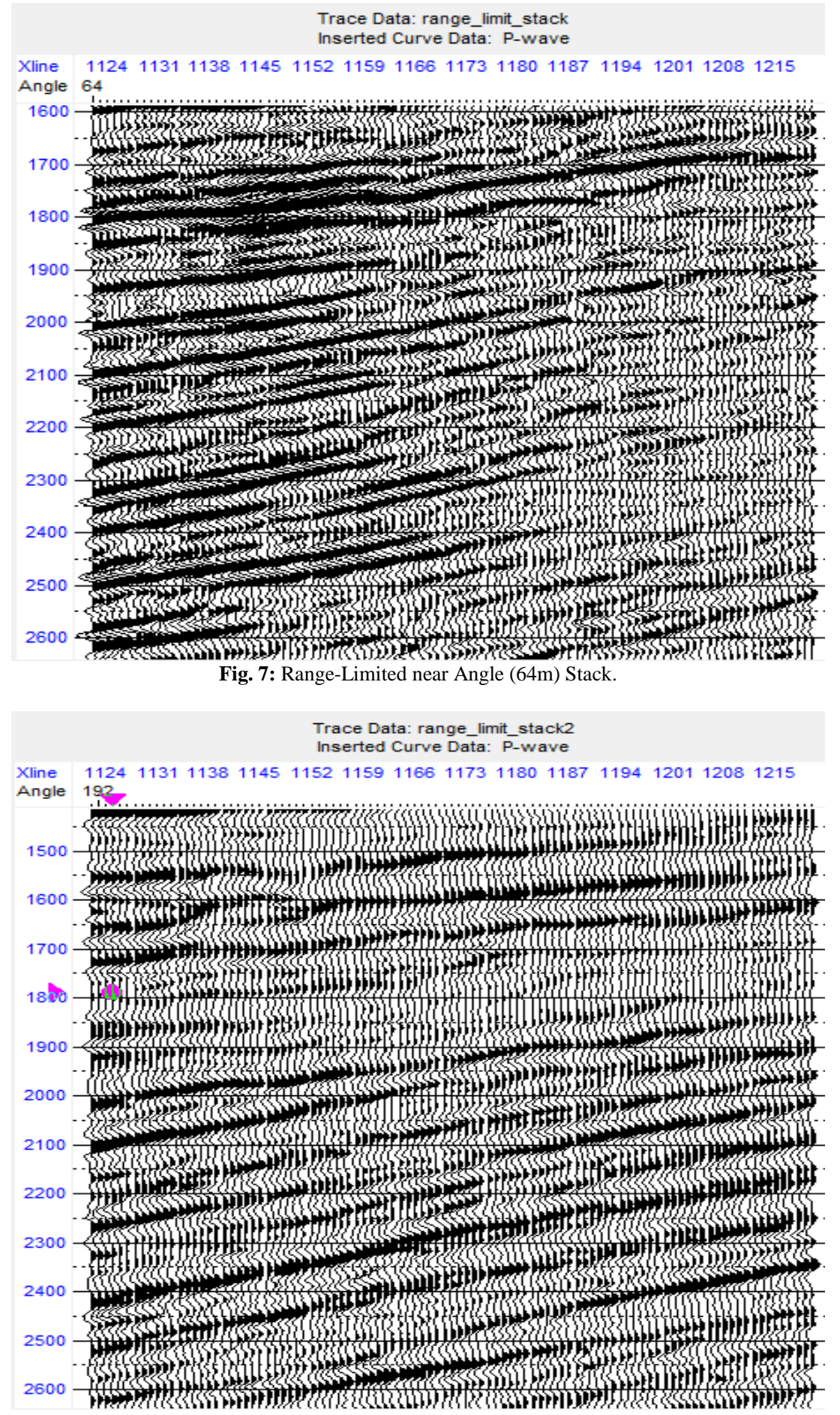

Fig. 8: Range-Limited Far Angle (192m) Stack.

\subsection{Model based inversion}

From each stack, a model each was created to get the near EI model (fig. 9) and far EI model (fig. 10) respectively from which inversion was done to generate the near (fig. 11) and far inversion results (fig. 12). 


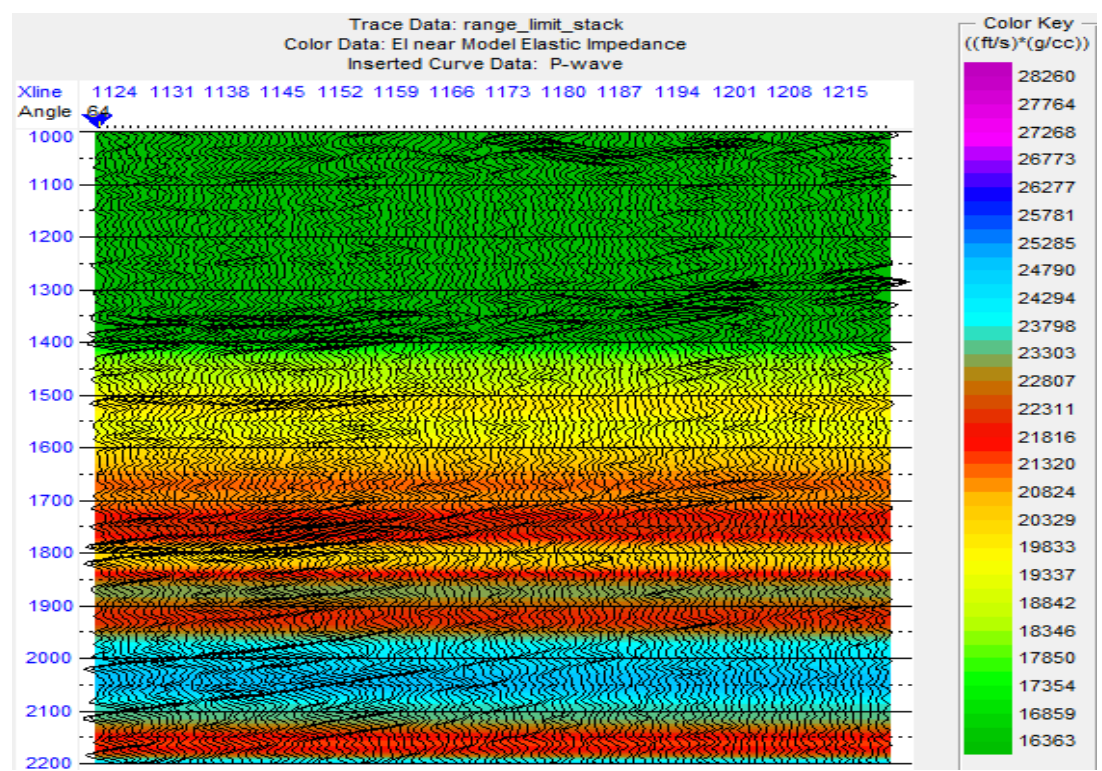

Fig. 9: Elastic Impedance (EI) near Model Display.

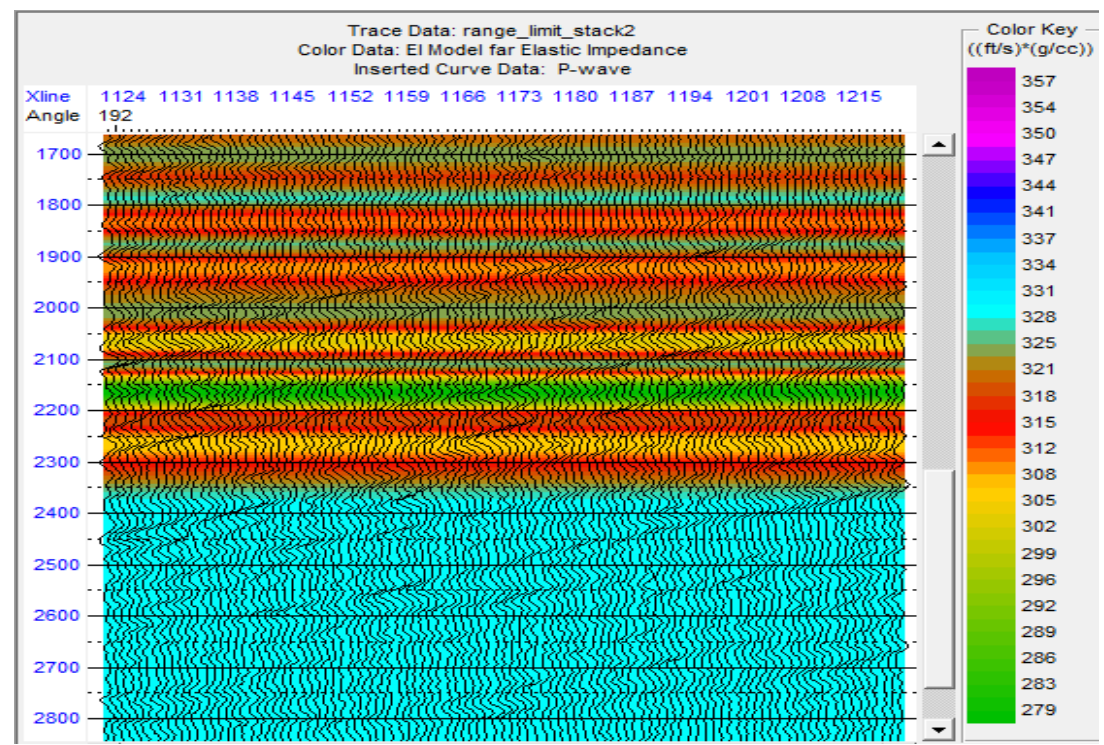

Fig. 10: Elastic Impedance (EI) Far Model Display.

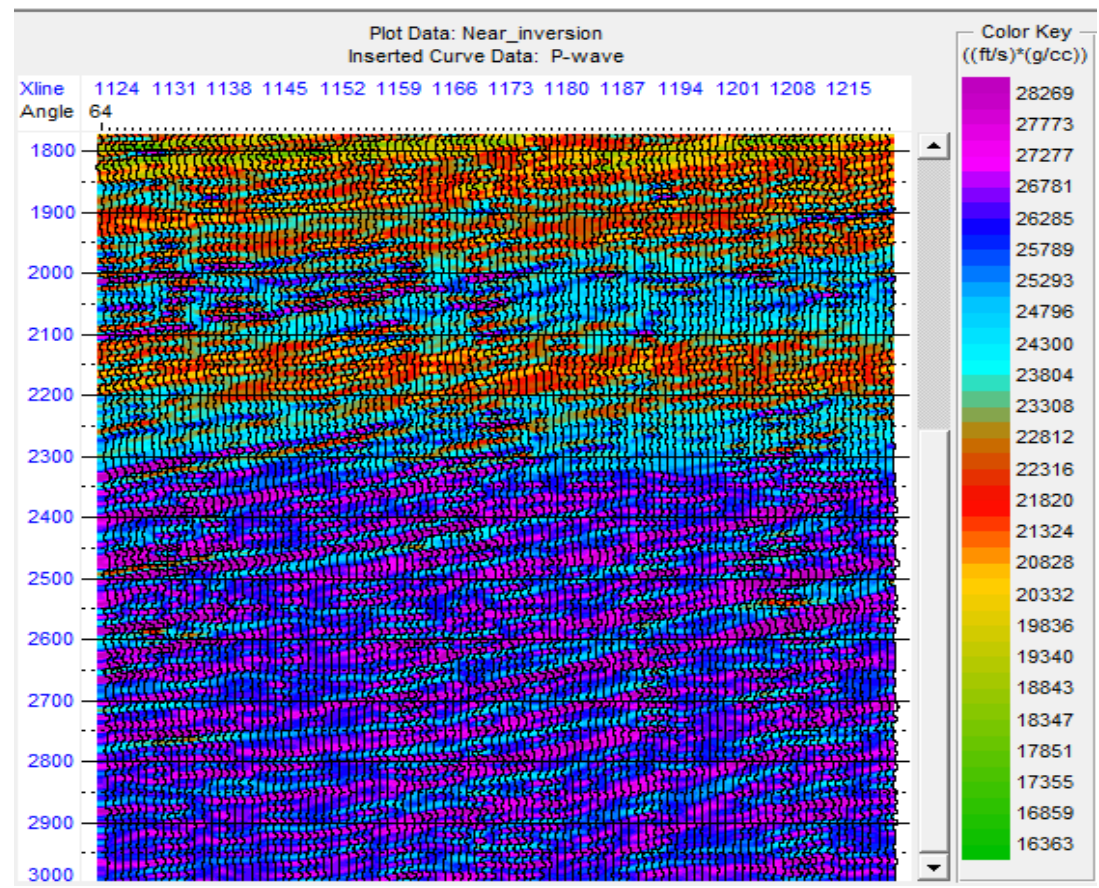

Fig. 11: Model Based Inversion Volume of Near- Angle Stack. 


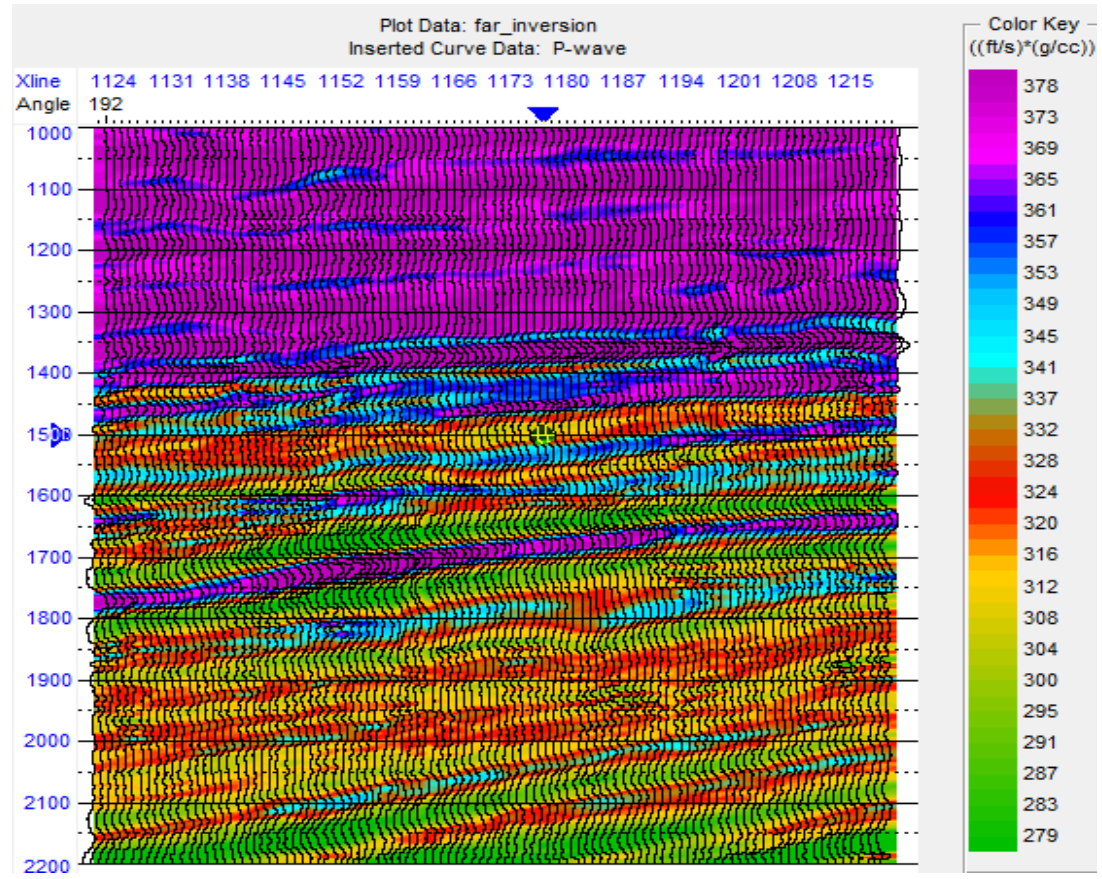

Fig. 12: Model Based Inversion Volume of Far- Angle Stack.

Two inversion results were now available. Two different colour scales were used since the impedance values were scaled differently. There is an improved definition of the gas sand on the far angle inversion with a stronger contrast represented by low values at the mapped seismic time window (fig. 13).

The near-angle inversion and far-angle inversion were compared by crossplotting the two volumes (fig. 14).

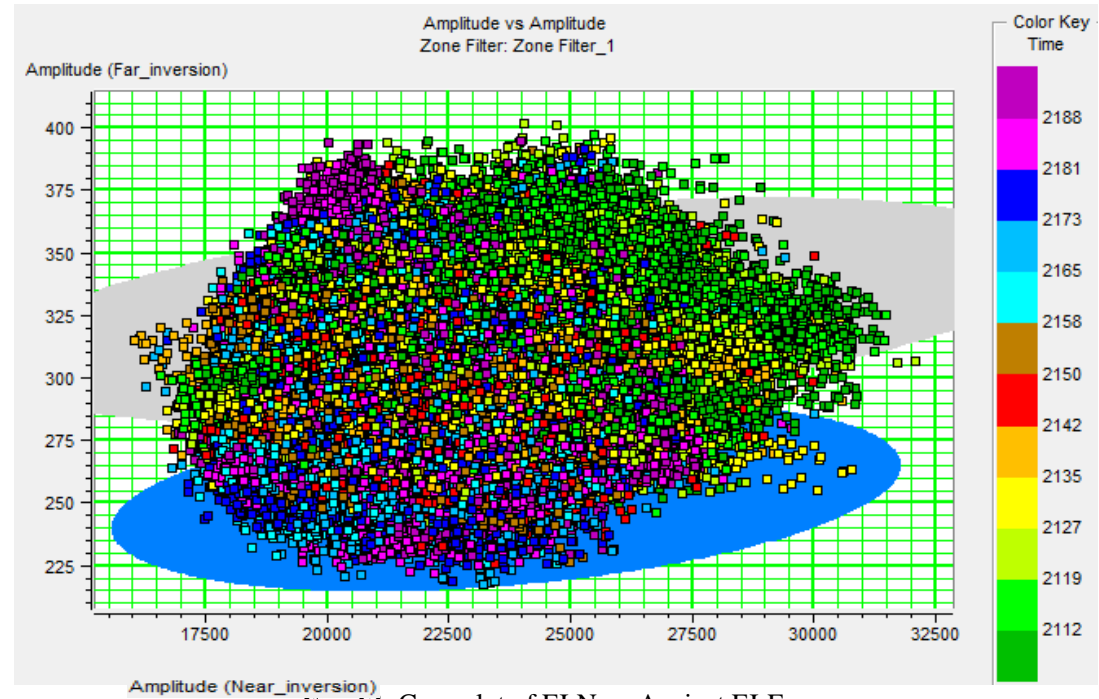

Flg. 13: Crossplot of EI-Near Against EI-Far.

If there were no AVO effects, the near and far impedances would be expected to be related by a straight line. In other words, there would be a single cluster. The attribute cross section confirmed the mapped zones in the seismic time window (fig. 14).

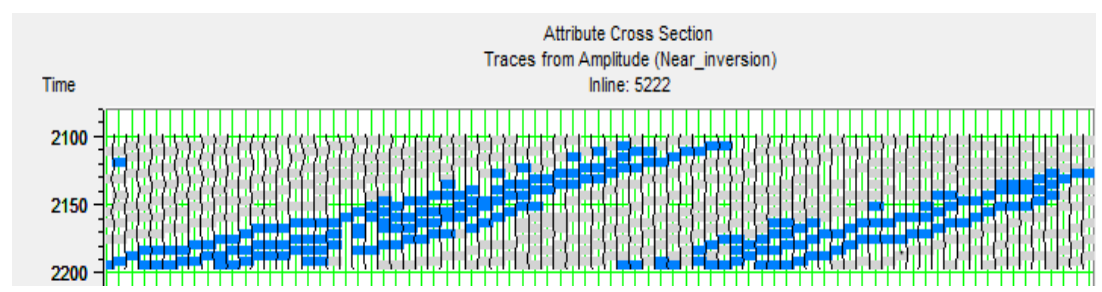

Fig. 14: Attribute Cross Section of the EI Plot with Mapped Zones.

Inserting the crossplot on the near-Inversion volume with the mapped zone, the visible top of gas (blue) on the zone of interest was noticed (fig. 15). This zone indicated where the elastic impedance at far-offsets is less than the elastic impedance at near-offsets moreover agreed with the Elastic Impedance results on the logs. 


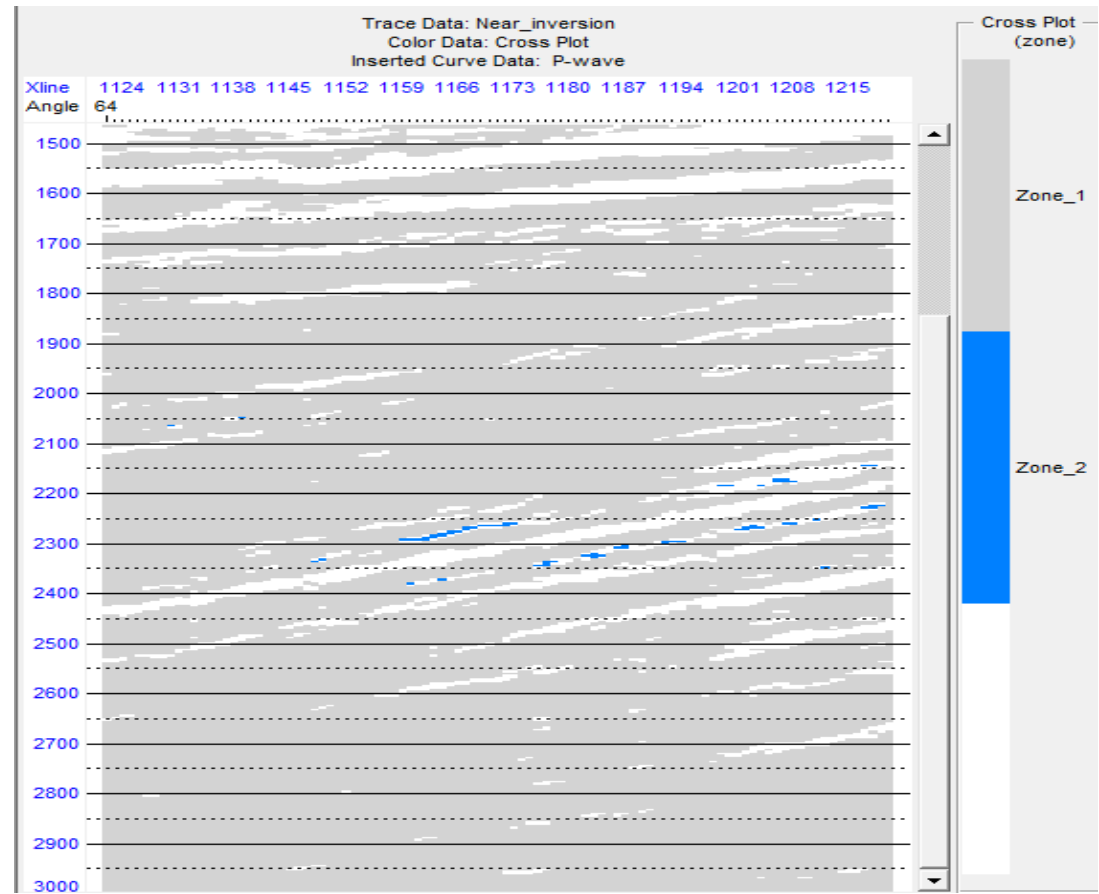

Fig. 15: Near Inversion Volume with Inserted Crossplot. Notice the Changes at the Sand Level which Is Indicative of Gas. That Is, the Elastic Impedance (EI) Is Much Lower on the Far Angle Stack Than the Near Angle Stack.

\section{Conclusion}

The elastic impedance attribute like other attributes enhanced the prestack data when the inversion was extended to handle AVO data. The Elastic Impedance showed anomalously low values at hydrocarbon areas moreover a dramatic change in its response when the inversion for Elastic Impedance at two different angles was done. There is a noticeable improved definition of the gas sand on the far angle inversion than on the near angle inversion.

\section{References}

[1] Adewoye O, Amigun J, O and Afuwai C, G. (2015). Lithostratigraphic interpretation and Seismic Attributes Analysis for reservoir characterization in some parts of Niger Delta. Pet Coal 57(1):76-84

[2] Cambois, G. (2001). How to obtain reliable S-impedance from P-wave data-advantages of elastic impedance. World Oil.

[3] Connolly, P. (1999). Elastic Impedance: The Leading Edge, April, 438-452. https://doi.org/10.1190/1.1438307.

[4] Ekine A S and Ibe A A (2013) Delineation of hydrocarbon bearing reservoirs from surface seismic and well log data (Nembe Creek) in Niger Delta oil field. J Appl Phys 4(3):26-30. https://doi.org/10.9790/4861-0432630. 